\title{
14. Policy Alchemy and the Magical Transformation of Aboriginal Society
}

\author{
David F. Martin \\ Anthropos Consulting and The Australian National University
}

Traditional culture has been stultified and degraded so that it has not moved from sorcery to the rule of reason, from polygamy to the equality of women with men and from 'pay-back' to the rule of law. - Helen Hughes (2007), Centre for Independent Studies

This chapter focuses on an issue to which Nicolas Peterson has directed our attention for nearly two decades (for example, Peterson 1991, 1998, 2005; Peterson and Taylor 2003): that many Aboriginal people, particularly but not only those living in remote regions, bring distinctive repertoires of values, world views and practices to their engagement with the general Australian society that have profound implications for the nature of that engagement. Critical social analysis of the situations of Aboriginal people must never ignore, for example, the historical role of the state; but neither must it avoid the central role of Aboriginal agency. My own research with Wik people living in Aurukun, western Cape York Peninsula (Martin 1993), ${ }^{1}$ showed how sorcery-or at least, accusations of it - is deeply implicated in the endemic disputation and violence that have become such a dominant feature of contemporary Aurukun life. I argued that Wik retaliation or 'payback', whether conducted openly through violence or secretly through sorcery, provides a particular instance of more general principles - those of reciprocity and equivalence - in the transactions of material and symbolic items through which autonomy and relatedness are realised. Like the flows of material goods, the exchanges of retribution serve to structure and reproduce the relationships not only between individuals but between collectivities (such as families). Sorcery is, thus, part of a repertoire of actions, some of them magico-ritual, by which Wik people attempt to impact on individual behaviour and on the ordering of social relations.

Aurukun has been the subject of intense scrutiny over recent decades because of its dramatically disintegrating social fabric, and it is almost an exemplar of the kind of remote Aboriginal community about which social and political commentators such as Hughes have had much to say in recent times, and at which

\footnotetext{
1 Nicolas Peterson recruited me to The Australian National University as a doctoral student, and was one of my thesis supervisors.
} 
a whole raft of policies has been directed by governments aiming to transform them. My view is that the necessity for change in Aurukun (and many other places like it) is real, and even more urgent now than it was three decades ago when I first went there as a young community worker. Yet many of the policy prescriptions seem on reflection to have a quasi-magical quality about them; the causal connection between the proposed framework and the intended outcome is obscure at best, even mystical, and certainly ideological. In this chapter, I use the trope of magic in an examination of some of the underlying assumptions in the writings of two prominent proponents of market mechanisms in Aboriginal affairs, which I characterise as being akin to alchemy-the medieval precursor to science that aimed, inter alia, to transmute base metals to gold.

The two individuals whose writings I refer to in this chapter are associated with two related institutions: development economist Helen Hughes from the Centre for Independent Studies, and Gary Johns, President of the Bennelong Society. The former organisation describes itself as "the leading independent public policy "think tank" within Australasia... [which] is actively engaged in support of a free enterprise economy and a free society under limited government where individuals can prosper and fully develop their talents' (<www.cis.org. au/aboutcis/aboutcis.html $>$ ). The Bennelong Society is a small lobby group in Aboriginal affairs established in 2001, which aims to 'promote debate and analysis of Aboriginal policy in Australia, both contemporary and historical' (<www.bennelong.com.au/aims.php $>$ ). Both had a major influence on the public debates around Aboriginal affairs policy during the Howard government era, and the legacy of that influence arguably continued in many aspects of the current Labor government's policy framework.

As the epigraph from Helen Hughes illustrates, some commentators and policy makers see phenomena such as sorcery as part of a 'degraded' traditional Aboriginal culture in troubled communities such as Aurukun, to be replaced with the 'rule of reason'. But are traditionally oriented Aboriginal people the only ones who subscribe to the power of seemingly irrational socially transformative techniques? The question must be asked: do some of the Aboriginal policy proposals of the Bennelong Society and the Centre for Independent Studies themselves follow the 'rule of reason'? Or are they more akin to the magical and irrational art of alchemy? ${ }^{2}$

\footnotetext{
2 My use here of the trope of Aboriginal policy 'alchemy' shares semantic space with Lea's (2008) assigning of a magical quality to Indigenous health policy making, but my concern in this chapter is a more limited one. In her account of the Northern Territory's Health Service, Lea maintains that government interventions to address Indigenous health issues operate through a 'magical circularity of interventionary perception', in which past policy failures necessitate ever-greater interventions. The magic of intervention arises when bureaucratic imagining that governmental categories define the totality of Aboriginal lives moves to the assumption that the only way forward is more governance (Lea 2008: 151).
} 


\section{The Alchemy of Aboriginal Policy Making}

European medieval alchemy was based on mystical and speculative philosophy, and aimed to achieve such goals as the transmutation of the base metals (particularly lead) into gold, a universal cure for disease and a means of indefinitely prolonging life. Much effort was invested in the search for the Philosopher's Stone-believed to mystically amplify the user's knowledge and capacity to achieve such goals. While the alchemists failed in these endeavours for reasons clearly established by modern science, they played a significant role in the development of chemistry (Moran 2000). Indeed, one of the founding fathers of science, Isaac Newton, was keenly interested in alchemy and its associated chemical experiments and evidently devoted more time to these inquiries than to his mathematics, planetary mechanics and the optics of colour (Guerlac 1977). In modern usage, the term 'alchemy' also infers an almost magical transformative process of change from one state to a different, putatively better and more valuable or desirable one.

It is thus, in my view, a suggestive metaphor in the Aboriginal policy arena. The medieval alchemists proceeded on their quest in ignorance of the objective nature of the base metals they sought to transmute to gold, and furthermore attempted to do so by irrational magical means. So, too, I suggest, do certain of the Aboriginal policy prescriptions of Helen Hughes and Gary Johns ignore or distort key characteristics of the Aboriginal 'substrate' in their quest to have its base and dysfunctional nature transmuted to the desirable form of the economically assimilated Australian citizen, through means that are 'quasimagical'. In the following section, I will outline just some of the anthropological findings on the principles of Aboriginal economic life to illustrate this distortion, and the quasi-magical means by which they propose Aboriginal people are to be transformed.

\section{Aboriginal 'Economic' Values: Policy's blank slate}

Anthropology enables us to recognise that what we understand as 'the economy' does not lie outside culture, but indeed is an intrinsic aspect of it (for example, in the Australian Aboriginal context: Austin-Broos 2003; Macdonald 2000; Martin 1993, 1995; Peterson 1993, 2005; Povinelli 1993; Schwab 1995; and see Altman, Kwok and Saethre, this volume). Trigger (2005) usefully summarises the literature in relation to how we are to understand the Aboriginal economy and the relationship between economy and culture in terms of pervasive Aboriginal values such as a strong ethos of egalitarianism and an associated pressure to conform to norms of equality, the pursuit of family and local group loyalties 
against notions of the 'common good', demand sharing as a mechanism working against material accumulation, and an underlying ideological commitment to continuity with the past that militates against the acceptance of change. Logically, such values would seem to have significant implications for the ways in which people engage with the general Australian society and its economy, and government policies and programs predicated on economic assimilation as a primary mechanism for addressing disadvantage (cf. Saethre, this volume).

A mere list as presented here does not, however, capture the true import and embeddedness of such values for many Aboriginal people. For example, as has been well documented, Australian Aboriginal societies can be aptly described as 'kinship polities', with kinship structuring not only 'private' familial relations, but also 'public' social, economic and political relations (for example, Sutton 2003: 178, 206ff.). At the same time, relations of kinship provide a foundational dimension of personal identity and indeed a certain structure to ethical frameworks - for example, the pervasive feature of a lack of a notion of the wider common good extending past local group and family boundaries (Martin 2001; Tonkinson 2007).

Particularly insightful here are the discussions by Peterson and Taylor (2003) and Peterson (2005) regarding the Aboriginal 'moral economy' — a term adapted in part from the work of E. P. Thompson (1991: 339-40). Peterson characterises the activities involved in acquiring a livelihood in the pre-colonial situation as being embedded in kinship and/or group relations. Production, in the sense at least of the products of foraging, was nearly always intimately linked with consumption, even indeed before the activity took place, through obligations and commitments established through the kinship system. Peterson proposes that after Aboriginal people in remote Australia and elsewhere entered the cash economy - many primarily through the welfare system - the cultural structuring of the Aboriginal economy involved an almost exclusive focus on circulation and consumption, rather than also on production (on further aspects of welfare and welfare colonialism, see Altman, Kwok, Ono and Saethre, this volume). He maintains that with circulation and consumption as the central features of economic activity, their focus turned to kinship, reciprocity and sharing practices. He suggests that in this context, the notion of 'moral economy' is useful to understand what is going on. By moral economy, he means the allocation of resources to the reproduction of social relations at the cost of profit maximisation and obvious immediate personal benefit. The Aboriginal moral economy is characterised by the centrality and persistence of sharing. As Peterson explains it:

Sharing is inseparable from the division of labour, the minimisation of risk and the managing of uncertainty; it is also at the heart of the production and reproduction of social relations, egalitarianism and 
the self. There are four elements to the Indigenous domestic moral economy. It is characterised by a universal system of kin classification that requires a flow of goods and services to produce and reproduce social relationships. The circulation of goods takes place within the framework of an ethic of generosity, informed by the social pragmatics of demand sharing, with open refusal rare, since it is seen as a rejection of relatedness. In such social contexts personhood is constituted through relatedness while at the same time it is associated with an egalitarian autonomy. (Peterson 2005: 5)

What is in some ways a complementary scheme for a modern hunter-gatherer 'mode of subsistence' has been proposed by Bird-David (1992), who argues that in most if not all aspects of what they do for a living, modern hunter-gatherers procure resources, even when they do so by means that are prototypical production activities for other peoples. By 'procure', the author refers to the Shorter Oxford Dictionary meaning of 'to bring about, to obtain by care or effort, to prevail upon, to induce, to persuade a person to do something'. While it is akin to 'harvest' in referring to gathering the resources of lands and waters, 'procure' also usefully pertains to the social environment as well. She argues that hunter-gatherers do not engage in production

in the full sense of the word, neither as understood by Marx as a cyclical process, where production and consumption are dialectically related, nor in the neo-classical sense, where production is all about the creation of resources, inextricably connected with re-investment...The extension of sharing practices to these activities, in the various ways it is done, fully or partially, directly or indirectly...reinforces the logic of procurement against the logic of production. (Bird-David 1992: 40)

Bird-David further argues that it follows that modern hunter-gatherers are not 'opportunists' - a term to which, along with 'foraging', she objects on the grounds that they are pejorative - but rather are committed to a 'logic of procurement' that is so deeply embedded in their world view and understandings of themselves that it is not dependent on the exclusive or even the continuing pursuit of hunting and gathering per se (1992: 40). She proposes that this 'hunter-gatherer mode of subsistence' is characterised by four interrelated prototypical features:

(a) Autonomous pursuit of activities directed to gaining resources. Individuals and families shift autonomously between different means of procuring resources in response to their circumstances and opportunities. 
(b) Variation over time (diachronic variation). These shifts do not follow any regular temporal pattern, but vary over time, and indeed over generations. Variety and flexibility are prominent over time.

(c) Variety at any given time (synchronic diversity). Often, diverse means for procuring resources are pursued simultaneously within the social group at its various levels. Variety and flexibility are also prominent at any given time.

(d) A continuous presence of the hunter-gatherer ethos. While individuals may shift frequently between different means of procuring resources, and engage variously with economic activities of the wider societies within which they live, 'procurement' as a means of gaining access to resources persists, as noted above, even when classical hunting and gathering is no longer practised. (Bird-David 1992: 38-41)

Within this framework, work for wages can itself be just one of the strategies adopted to gain food and other material resources, combined as opportunities arise and in no fixed way (Bird-David 1992: 28). Further, 'procurement' (for which we can safely substitute foraging, in my view, despite Bird-David's concerns) is an entirely different social, cultural and economic institution to 'work'. Foraging can certainly at times be extremely arduous, especially in harsh environments (for example, Cane 1987, with regard to Western Desert Aborigines), but it contrasts with the imposed regularity of work and indeed its regulation, purposes and economic and social entailments.

In this context, it should be noted, there is no Wik Mungkan equivalent to the concept of 'work', and hunting is no more 'work' than are card games, although it might take more physical effort. ${ }^{3}$ Both can be seen in Bird-David's terms as procurement, as opportunistically accessing resources that exist a priori rather than only after they have been 'produced'. What's more, successful hunting for Wik people, like successful gambling, involves in part the individual's use of magical means to manipulate the relevant environment (Martin 1993); it also entails maximising opportunities and minimising effort. The demand sharing of which Peterson writes - through which one opportunistically seeks both tangible and intangible resources from others - is another aspect of this same foraging concept of economy.

\footnotetext{
3 Peter Sutton (personal communication, 2008) observes that there is no translation of the term 'work' in any Aboriginal language known to him. Nicolas Peterson (personal communication, 2008) advises that there is a term used by Yolngu for 'work' - djama - but that it is a Macassan loan word. It is also used by Yolngu for other activities such as ceremony, basket weaving, and so forth (Williams and Mununggurr 1994: 75). This is, however, understood better as productive activity across a range of domains than as 'work' within a market economy with its imposed regularity and regulation, purposes, and economic and social entailments.
} 
The features of Peterson's Aboriginal 'moral economy', such as the nexus between personhood and relatedness established through sharing, and those of Bird-David's hunter-gatherer mode of subsistence in which one forages for already existing resources in a flexible, opportunistic framework in which autonomy is maximised, provide insight into the factors underlying the extraordinary persistence of distinctive ways of life amongst people who can be many generations away from their hunter-gatherer forebears (Gibson 2010). I turn now to a brief examination of how Johns and Hughes would change these ways of life.

\section{Market Mechanisms: The modern Philosopher's Stone?}

I noted earlier that the alchemists invested much effort in the search for the Philosopher's Stone, which they thought would mystically enable them to achieve their goals, including that of transmutation. I also noted that, as modern science demonstrates, the alchemists were ignorant of the objective characteristics of the base metals they sought to transform. An equivalent ignorance of the nature of Aboriginal societies, including but not limited to their 'economic' values, is evinced by Hughes in particular but also by Johns.

Other commentators have noted Hughes' scant regard for the facts of the matters on which she writes in Aboriginal affairs, and the highly polemical approach she takes (Hunter 2008; Rowse 2007). Hughes certainly demonstrates an alchemist's ignorance of the base state she wishes to transform:

Aborigines and Torres Strait Islanders are frustrated because they cannot express themselves in English in speech or writing. They feel that life is slipping through their fingers because they do not have the job opportunities, incomes and living standards of other Australians. They resent their separation from the wider Australian community. They do not want to interact with other Australians and the rest of the world merely as 'cultural exhibits' in 'living museums', but also through mainstream work and recreation. (Hughes and Warin 2005: 13)

Even a minimal reading of relevant literature, including but not limited to that from anthropologists, should have dissuaded Hughes from claiming that such views, motives and emotions are held in common amongst Australian Indigenous people. Johns has at least accessed some of the relevant anthropological and other work, but has taken a very reductionist and motivated reading of it. For instance, he states: 
Too frequently 'culture' has been used to veil or excuse bad behaviour. For example, it has been recognised for a long time that Aboriginal economies in remote areas operate by 'demand sharing' or 'humbugging' (that is, where kin demand the immediate use of whatever a person owns), rather than by individual accumulation of physical or financial capital (Martin 1995: 19). Yet there is no suggestion Aborigines should be advised that this is why they are poor, or that this aspect of the culture must change. (Johns 2008: 68)

Let us examine the alchemical logic of this statement. 'Humbugging' - an Aboriginal English term that has now entered the everyday parlance of Aboriginal affairs bureaucrats - by Johns' account is the fundamental principle by which Aboriginal economies operate, and (he implies) changing this bad behaviour will enable Aboriginal people to be transmuted from their current base state to a different, richer one (cf. Altman, this volume). Quasi-magical causality indeed, given that as the discussion of demand sharing in the previous section illustrates, and whatever its problematic or unintended consequences are in an era of welfare dependency, it is not simply 'bad behaviour' but a practice deeply implicated in the nexus between personhood and relatedness. To change the practice must necessarily involve an inculcation of a profound reordering of social and psychological worlds that cannot rationally be addressed by people being 'advised' to change.

Johns is alert to the real dilemmas posed for the modernisation project by certain deeply embedded Aboriginal values and practices of ancient origin. In this respect, he is arguably more honest than Cape York's Richard Ah Mat (2003), who in claiming that modernisation is in fact essential to cultural survival, elides the profound personal and cultural transformation that would necessarily be entailed. On the other hand, it is a theme to which a good number of anthropologists (of varying political persuasions) as well as others have paid attention (for example, Brunton 1993; Cowlishaw 1998; Elkin 1951; Folds 2001; Martin 1993, 1995, 2001; Peterson 1998, 2005; Stanner 1979; Sutton 2001, 2009). Sutton, for example, raises a range of issues that overlap directly with those of Johns, but based on a detailed and nuanced understanding of remote Aboriginal societies. Johns does not refer to Sutton's work, or that of virtually any other relevant researcher. Consequently, in the apparent absence of any significant direct experience of Aboriginal societies, he is as ignorant of the true nature of these societies as any alchemist was of the true nature of base metals.

Both Hughes and Johns would rely on market mechanisms as a primary driver to transform Aboriginal people's values. Their writings instance the morally reformative character of the discourse around market-based policy frameworks (Martin 2001). In no small part, the justification for this new order is established by defining the current state of much of Aboriginal Australia in terms of its 
inherent dysfunctionality, thereby legitimating a focus on transforming Aboriginal communities and lives in particular directions. Johns, for example, pathologises not only Aboriginal culture, but also the totality of Aboriginal social life itself in remote Australia. He claims:

The uncomfortable fact is that, having recognised for decades the impediment that Aboriginal culture poses to success, policy-makers nevertheless chose cultural observance over success. Such choices ensure that the 'cargo cult'... is alive and well. The consequence is that if people are maladapted to modern society they are, in fact, trapped in a culture of bad behaviour, a 'sick society'...that continues to reproduce its awful daily mores. (Johns 2007: 68)

Those who are not adapted to modern society, we can reasonably infer, are trapped in immoral cultures. Another particularly clear example of this moral cast is provided by Pearson (2000a, 2000b), with his influential call for the fundamental necessity of Aboriginal engagement with what he terms the 'real' economy, which is constructed in quintessentially moral rather than formal economic terms (Martin 2001). A real economy, Pearson tells us, involves a demand for both social and economic reciprocity. The traditional Aboriginal subsistence economy and the contemporary market one are, in Pearson's view, 'real' economies, entailing as they do both rights and responsibilities and are thus, we can surmise, 'moral' economies (although not in the sense in which Peterson has used the term as discussed previously).

Directly related to the previous point, the morally reformative nature of work itself is stressed; work is not just about production, or indeed about wages, but about making one's way in the world as an independent and self-sufficient actor. Through work, one thereby discharges one's obligations to society in general but in a manner abstracted from commitments to particular networks and communities and to particular locales (Martin 2001). Johns expresses this neatly:

Land rights will only be useful for those few who can create a life on the land...Land rights, nevertheless, are legal and political reality, so the goal must be to make them work. The way to make them work is to stop treating Aborigines as exotica and regard them as being able to abide by the same civic obligations and respond to the same economic incentives as anyone else. (Johns 2007: 1)

In Johns' and Hughes' work, reflecting a long historical propensity in Aboriginal affairs, there is a strong focus on the moral reformation of the individual, abstracted from his or her social and cultural nexus, as opposed to a preceding focus on Aboriginal groups and communities (Martin 2001). One illustration 
of this move can be seen in Hughes' and Johns' rejection of policies framed around self-determination and other such collective rights-based frameworks (which Hughes [2005] sees as evidencing imposed socialism) in place of those which emphasise human capital development and the responsibility of the individual to adapt and change (for example, Hughes 2005; Johns 2007, 2008; cf. Saethre, this volume). This emphasis is consistent with the requirements of today's free-market economies, based (at the ideological level if not in practice) on the essentially unrestricted flows of goods and services, including a mobile labour force with portable skills willing and able to move to wherever the work is. The epitome of this of course are the fly-in-fly-out mining operations in remote regions of Australia where Aboriginal people often make up a substantial proportion of the population, but where, with some notable exceptions in recent years (for example, the Argyle diamond mine in the Kimberley and the Century zinc mine in Queensland's Gulf country), they have had little involvement in mine-site employment.

Finally, the use by Hughes and Johns of terms such as 'choice' and 'incentives' is drawn from and consistent with market-based policy frameworks. This work, and indeed much Aboriginal policy, especially that developed over the past decade, is predicated on the implicit assumption that Aboriginal people will naturally, given the opportunity, choose lifestyles and adopt associated values that correlate with economic integration, or that if they do not, a carrot-andstick approach can be used to achieve this. This assumption is well illustrated in a quote from Helen Hughes in a letter to the editor of Quadrant Magazine:

We argued (Hughes and Warin 2005) that because there are no clear and simple individual property rights in land (including long-term, 99 year leases), there are no leafy Aboriginal suburbs and no successful landbased businesses. (Hughes 2005)

Incentives by definition, however, are not culture or value free. The incentives that presumably drive many Australians to work in the ways and to the extent that they do-pride in the inherent worth of what they are doing, material comfort, financial security and autonomy as individuals or family units, paying off the mortgage on the family home, supporting their children through education as a valued goal in itself - cannot be assumed to apply equally across cultures. In particular, it cannot be assumed that such inducements apply amongst at least a substantial proportion of Aboriginal people, including but not limited to those living in remote and perhaps more traditionally orientated communities (see, for example, Peterson 2005; Tonkinson 2007; Trigger 2005; and see Kwok and Saethre, this volume).

My own experience and observation are that the possibility of living in a leafy suburb would of itself provide little if any inducement to change economic 
behaviour for many remote-dwelling Aboriginal people. For example, I have observed the case of a person from a remote community for whom living for only a few months in just such an environment as Hughes extols led to deep psychological distress and psychosomatic illness. For many (although certainly not all) remote-dwelling Aboriginal people, moving permanently away from kin and country is a very confronting notion, and potentially higher material wealth provides little incentive at all if it involves breaking these connections, which are so intrinsic to who one is. To be able to enable significant numbers of Aboriginal people to make such a move on a sustained and sustainable basis without simply changing the geographical location of social dysfunction will require more sophisticated policy levers than are provided by simplistic assumptions about choice and incentives.

\section{Concluding Remarks}

The foregoing should not be taken as an argument from an entrenched 'left' position against the necessity for change. There is, in my view, an unassailable case for the transformation of remote Aboriginal communities; maintenance of the status quo is indefensible (Martin 2001). But, both 'left' and 'right' have exhibited not a little of the alchemic tendencies of which I have accused Hughes and Johns. Where the right has wished to transmute remote-dwelling Aboriginal people from the debased nature of communalism and social dysfunction to the gold of autonomous economic actors, the left has proposed they be transmuted from the base state of dispossessed anomie to the gold of the enculturated Aboriginal citizen. For the left, the Philosopher's Stone has been the granting of rights under the rubric of self-determination, whereas for the right it has been the market. Both have their magical illusions.

Ultimately, there is always the possibility that while health, educational, income and other socioeconomic indicators for particular Aboriginal groups or communities can be seen as arising from continuing discrimination and exclusion by the dominant society, they could also in part be the entailments of distinctive lifestyles and deeply embedded and perduring ways of being and acting in the world (for a striking example from 'settled' Australia, see Kwok, this volume). A difficult philosophical, ethical and political question arises, then, as to what extent diversity of certain forms can be accepted or even encouraged in a pluralist society, when they could entail very significant disparities in socioeconomic status (Martin 2005).

Nonetheless, Aboriginal policy debates typically avoid meaningful consideration of the demonstrable fact-one to which, as noted at the beginning of this chapter, Nicolas Peterson has directed our attention for nearly two decades- 
that many Aboriginal people, particularly but not only those living in remote regions, bring distinctive repertoires of values, world views and practices to their engagement with the general Australian society. This avoidance poses a major impediment to establishing appropriate support for the necessary processes of sustainable social, economic and cultural transformations in Aboriginal societies - and indeed to the changes needed in the mechanisms through which government promotes and supports such transformations. For, unless Aboriginal people themselves are actively involved in and ultimately committed to such changes, history shows us that they will be resisted. An Aboriginal affairs policy framework as proposed by Hughes and Johns will end, like the endeavours of the missionaries at Jigalong in the far Western Desert (Tonkinson 1974), as another failed crusade, but this time conducted by the alchemists of the market economy, and with consequences for Aboriginal people on a far greater scale.

\section{References}

Ah Mat, R. 2003. The moral case for Indigenous capitalism. Paper presented at Native Title on the Ground Conference, Australian Institute of Aboriginal and Torres Strait Islander Studies, Alice Springs, 3-5 June 2003, <http:// ntru.aiatsis.gov.au/conf2003/papers/ahmat.pdf>

Austin-Broos, D. 2003. Places, practices, and things: the articulation of Arrernte kinship with welfare and work. American Ethnologist 30 (1): 118-35.

Bird-David, N. 1992. 'The hunting and gathering mode of subsistence': culturesensitive observations on the Nayaka and other modern hunter-gatherers. Man [n.s.] 27 (1): 19-44.

Brunton, R. 1993. Black Suffering, White Guilt?: Aboriginal Disadvantage and the Royal Commission into Deaths in Custody. West Perth: Institute of Public Affairs.

Cane, S. 1987. Australian Aboriginal subsistence in the Western Desert. Human Ecology 15 (4): 391-434.

Cowlishaw, G. 1998. Erasing culture and race: practising 'self-determination'. Oceania 68 (3): 145-69.

Elkin, A. P. 1951. Reaction and interaction: a food gathering people and European settlement in Australia. American Anthropologist 53: 164-86.

Folds, R. 2001. Crossed Purposes. The Pintupi and Australia's Indigenous Policy. Sydney: UNSW Press. 
Gibson, L. 2010. 'Who you is?': Work and Identity in Aboriginal New South Wales. In I. Keen (ed), Indigenous Participation in Australian Economies, pp 127-140. Canberra: ANU E Press.

Guerlac, H. 1977. Book review of The Foundations of Newton's Alchemy or, 'The Hunting of the Greene Lyon', Betty Jo Teeter Dobbs. The Journal of Modern History 49 (1): 130-3.

Hughes, H. 2005. Native title's disasters. Letter to the Editor. Quadrant Magazine (July-August).

Hughes, H. 2007. Lands of Shame: The Deprivation of Australian Aborigines and Torres Strait Islanders. Executive Highlights No. 470, Centre for Independent Studies, Melbourne, <http://www.cis.org.au>

Hughes, H. and J. Warin, 2005. A New Deal for Aborigines and Torres Strait Islanders in Remote Communities. Issue Analysis 54, Centre for Independent Studies, St Leonards, NSW, <http://www.cis.org.au>

Hunter, B. H. 2008. 'Revisiting the role of rhetoric in economics'; a book review of Lands of Shame: Aboriginal and Torres Strait Islander 'Homelands' in Transition, by Helen Hughes. The Economic Record 84 (265): 279-81.

Johns, G. 2007. Making Land Rights Work. Occasional Paper, March 2007, Bennelong Society, Melbourne, <http://www.bennelong.com.au>

Johns, G. 2008. The Northern Territory intervention in Aboriginal affairs: wicked problem or wicked policy? Agenda 15 (2): 65-84, <http://epress.anu. edu.au/agenda/015/02/pdf/whole.pdf>

Lea, T. 2008. Bureaucrats and Bleeding Hearts: Indigenous Health in Northern Australia. Sydney: UNSW Press.

Macdonald, G. 2000. Economies and personhood: demand sharing among the Wiradjuri of New South Wales. In G. Wenzel, G. Hoverlrud-Broda and N. Kishigami (eds), The Social Economy of Sharing: Resource Allocation and Modern Hunter-Gatherers, Senri Ethnological Studies 53, National Museum of Ethnology, Osaka.

Martin, D. F. 1993. Autonomy and Relatedness: An Ethnography of Wik People of Aurukun, Western Cape York Peninsula. PhD Thesis, The Australian National University, Canberra.

Martin, D. F. 1995. Money, Business and Culture: Issues for Aboriginal Economic Policy. CAEPR Discussion Paper No. 101, Centre for Aboriginal Economic Policy Research, The Australian National University, Canberra. 
Martin, D. F. 2001. Is Welfare Dependency 'Welfare Poison'? An Assessment of Noel Pearson's Proposals for Aboriginal Welfare Reform. CAEPR Discussion Paper No. 213, Centre for Aboriginal Economic Policy Research, The Australian National University, Canberra.

Martin, D. F. 2005. Rethinking Aboriginal community governance: challenges for sustainable engagement. In P. Smyth, T. Reddel and A. Jones (eds), Community and Local Governance in Australia, pp. 108-27. Sydney: UNSW Press.

Moran, B. T. 2000. Alchemy, chemistry and the history of science. Studies in History and Philosophy of Science 31 (4): 711-20.

Pearson, N. 2000a. Our Right to Take Responsibility. Cairns, Qld: Noel Pearson and Associates.

Pearson, N. 2000b. Passive welfare and the destruction of Indigenous society in Australia. In P. Saunders (ed.) Reforming the Australian Welfare State. Melbourne: Australian Institute of Family Studies.

Peterson, N. 1991. Cash, commoditisation and authenticity: when do Aboriginal people stop being hunter-gatherers? In N. Peterson and T. Matsuyama (eds), Cash, Commoditisation and Changing Foragers, pp. 67-90. Senri Studies No. 30, National Museum of Ethnology, Osaka.

Peterson, N. 1993. Demand sharing: reciprocity and the pressure for generosity among foragers. American Anthropologist 95 (4): 860-74.

Peterson, N. 1998. Welfare colonialism and citizenship: politics, economics and agency. In N. Peterson and W. Sanders (eds), Citizenship and Indigenous Australians: Changing Conceptions and Possibilities, pp. 101-17. Cambridge: Cambridge University Press.

Peterson, N. 2005. What can the pre-colonial and frontier economies tell us about engagement with the real economy? Indigenous life projects and the conditions for development. In D. Austin-Broos and G. Macdonald (eds), Culture, Economy and Governance in Aboriginal Australia, pp. 7-18. Sydney: Sydney University Press.

Peterson, N. and J. Taylor, 2003. The modernising of the Indigenous domestic moral economy. The Asia Pacific Journal of Anthropology 4 (1-2): 105-22.

Povinelli, E. A. 1993. Labor's Lot: The Power, History, and Culture of Aboriginal Action. Chicago: University of Chicago Press.

Rowse, T. 2007. Land of confusion. Australian Policy Online. Melbourne: Swinburne Institute of Technology, <http://www.sisr.net/apo/rowse.pdf> 
Schwab, R. G. 1995. The Calculus of Reciprocity: Principles and Implications of Aboriginal Sharing. CAEPR Discussion Paper No. 100, Centre for Aboriginal Economic Policy Research, The Australian National University, Canberra.

Stanner, W. E. H. 1979. Continuity and change among the Aborigines. In White Man Got No Dreaming, Essays 1938-1973. Canberra: The Australian National University Press.

Sutton, P. 2001. The politics of suffering: Indigenous policy in Australia since the 1970s. Anthropological Forum 11 (2): 125-73.

Sutton, P. 2003. Native Title in Australia: An Ethnographic Perspective. Cambridge: Cambridge University Press.

Sutton, P. 2009. The Politics of Suffering: Indigenous Australia and the End of the Liberal Consensus. Carlton, Vic.: Melbourne University Press.

Thompson, E. P. 1991. Customs in Common. London: The Merlin Press.

Tonkinson, R. 1974. The Jigalong Mob: Aboriginal Victors of the Desert Crusade. Menlo Park, Calif.: Cummins.

Tonkinson, R. 2007. Aboriginal 'difference' and 'autonomy' then and now: four decades of change in a Western Desert society. Anthropological Forum 17 (1): 41-60.

Trigger, D. 2005. Mining projects in remote Australia: sites for the articulation and contesting of economic and cultural futures. In D. Austin-Broos and G. Macdonald (eds), Culture, Economy and Governance in Aboriginal Australia, pp. 41-62. Sydney: Sydney University Press.

Williams, N. and D. Mununggurr 1994 [1989]. Understanding Yolngu signs of the past. In R. Layton (ed.) Who Needs the Past: Indigenous Values and Archaeology, pp. 70-83. London: Routledge. 